\title{
Bacteriologic and plasmid analysis of etiologic agents of conjunctivitis in Lagos, Nigeria
}

\author{
Bamidele Abiodun Iwalokun • Afolabi Oluwadun • Kehinde Adewale Akinsinde • \\ Mary Theressa Niemogha $\cdot$ Fransisca Obiageri Nwaokorie
}

Received: 20 February 2011 / Accepted: 15 March 2011 /Published online: 5 April 2011

(C) The Author(s) 2011. This article is published with open access at Springerlink.com

\begin{abstract}
Background Conjunctivitis, an inflammation of the conjunctiva, is one of the most common eye problems affecting all age groups in Nigeria. A better understanding of its epidemiology and the antibiotic susceptibility of etiologic bacterial agents is crucial for the initiation of preventive and therapeutic measures. This study determined the distribution and patterns of bacterial infections in Nigerian patients with conjunctivitis. Antibiotic resistance patterns and the plasmid profiles of these pathogens were also investigated. Methodology A total of 83 consecutive and non-duplicate conjunctival specimens were collected from patients attending eye clinics at three different hospitals in Lagos, Nigeria, between February and September 2010. Specimens were cultured on standard bacteriologic media and the recovered isolates speciated using standard techniques. Susceptibility of
\end{abstract}

B. A. Iwalokun $(\bowtie)$

Department of Biochemistry Nutrition,

Nigerian Institute of Medical Research (NIMR),

Yaba, Lagos, Nigeria

e-mail: bamwal@yahoo.com

A. Oluwadun

Department of Medical Microbiology and Parasitology,

Olabisi Onabanjo University,

Sagamu, Ogun State, Nigeria

K. A. Akinsinde $\cdot$ M. T. Niemogha $\cdot$ F. O. Nwaokorie Department of Molecular Biology and Biotechnology, Nigerian Institute of Medical Research (NIMR),

Yaba, Lagos, Nigeria

\section{T. Niemogha}

Department of Medical Microbiology and Parasitology,

University of Benin,

Benin, Edo State, Nigeria pathogens to antibiotics and plasmid DNA extraction were carried out by disk diffusion and alkaline lysis methods. Conjugation experiment was done with rifampicin-resistant Escherichia coli $\mathrm{DH} 5 \alpha$ as the recipient cell. Data were analyzed using the chi-square test.

Results All the specimens were culture-positive, yielding a total of 155 bacterial isolates. Gram-positive cocci comprising Staphylococcus aureus (27.7\%) and coagulase-negative Staphylococcus sp. (22.6\%) accounted for $50.3 \%$ (78 of $155)$ of conjunctivitis cases, followed by Gram-positive bacilli (22.6\%), Gram-negative bacilli (21.3\%), and Gramnegative cocci $(4.5 \%)$. Corynebacterium spp. were the most commonly isolated Gram-positive bacilli accounting for $16.1 \%$ of conjunctivitis cases. Pseudomonas aeruginosa topped with $9.7 \%$ as the most commonly isolated Gramnegative bacilli. Other Gram-negative bacilli in order of their isolations were E. coli (6.5\%), Proteus sp. (3.2\%), Klebsiella sp. (1.9\%), and Enterobacter aerogenes (1.9\%). Moraxella spp. were the only Gram-negative cocci isolated, and they accounted for $4.5 \%$ of the total conjunctival infections. Further analysis of the complexity of infections showed that 25 specimens elicited mono-infections, while cases of polymicrobial infections caused by two pathogens and three or more pathogens constituted $51.8 \%$ and $18.1 \%$ of conjunctivitis specimens screened, respectively. The disparity in the percentage contribution of three infection patterns was significant $(P<0.05)$. Antibiotic susceptibility testing revealed chloramphenicol and ofloxacin as the least and most active antibiotics tested as $99(63.9 \%)$ and 149 (96.1\%) of the 155 recovered isolates were sensitive to them. On the whole, the least susceptible pathogen was $P$. aeruginosa with sensitivities ranging from $20 \%$ to $80 \%$, while Moraxella sp. represented the most sensitive pathogen with sensitivities ranging from $71.4 \%$ to $100 \%$. Other bacterial isolates also elicited antibiotic sensitivities in the range of $33.3-100 \%$. A 
total of 101 isolates were screened for plasmids, of which 45 harbored plasmids, yielding a plasmid frequency of $44.6 \%$. Conjugal transfer of resistance to chloramphenicol, ampicillin, and streptomycin was detected in the transconjugants after the mating experiment. The antibiotic resistances were transferred either singly or in combination from six of the seven selected donor strains. The antibiotic resistance pattern transferred by these donor strains was partial and was associated with the transfer of $\mathrm{R}$ plasmids of sizes 21.3, 15.2 , and $5.0 \mathrm{~kb}$ from three of the six transferable strains. The frequencies of transfer of antibiotype or $\mathrm{R}$ plasmids to the transconjugants ranged from $1.8 \times 10^{-7}$ to $1.4 \times 10^{-5}$ transconjugants per donor strain.

Conclusion Conjunctivitis as an eye problem in Lagos is polymicrobial with infections associated with transferable $\mathrm{R}$ plasmids for chloramphenicol, ampicillin, and streptomycin. Continuous surveillance of conjunctivitis in relation to etiology, drug susceptibility, and plasmid transferability in the study area is therefore recommended.

Keywords Conjunctivitis · Bacterial pathogens $\cdot$ Lagos

\section{Introduction}

Both Gram-positive and Gram-negative bacteria are increasingly becoming important both clinically and therapeutically as biological agents of ocular infections throughout the world. Various forms of ocular infections caused by pathogenic bacteria have been reported by different investigators. They include conjunctivitis, cornea perforation, orbital cellulitis, endophthalmitis, panophthalmitis and dacryocystitis, internal and external hordeolum, keratitis, scleritis, and canaliculitis [1-3]. Some of these infections carry poor prognosis as patients are at risk of losing either their sights or life, or both $[2,4]$. This has necessitated the prompt detection of the etiologic agent and the timely institution of appropriate antibiotic treatment for patients with ocular infections. In Nigeria, conjunctivitis is one of the most common eye problems that affect all age groups. An epidemic of conjunctivitis was reported in Nigeria in 1971 [5]. In neonates, the incidence of conjunctivitis has been reported to be 18 per 1,000 live births, and predisposing factors have been found to include vaginal delivery, asphyxia neonatorum, and prolonged rupture of the membrane [6]. A previous epidemiological study carried out by Abiose et al. [7] revealed conjunctivitis as among the causes of ophthalmic defects needing urgent medical attention in $10.4 \%$ of the 5,220 post-primary school Nigerian children screened. The routes of transmission of conjunctivitis have been identified to include air droplets, use of contaminated water for eye wash, hand to eye contact, and endogenous sources [2]. The pathology of conjunctivitis is symptomized by redness of the eye, grittiness, photophobia, and watery discharge. There may also be cornea involvement leading to subepithelial and epithelial keratitis. If untreated, conjunctivitis may degenerate pathologically to sight and life-threatening complications $[8,9]$. Therefore, the early identification of etiologic agents and prompt institution of appropriate antibiotic therapy are essential for optimal eye care and restoration of a good eye health. Studies by investigators from other countries indicate that Gram-positive and Gram-negative bacteria are the most commonly isolated pathogens in patients with conjunctivitis, but variations exist in aetiologies, drug susceptibilities of pathogens, and antibiotic resistance mechanisms. Grampositive bacteria such as Staphylococcus aureus, noncoagulase-positive Staphylococci, Bacillus sp., Corynebacterium sp., Streptococcus pneumoniae, Streptococcus pyogenes, and Streptococcus viridans have been implicated as aetiologies of conjunctivitis in patients [8, 10, 11]. In Gramnegative-mediated conjunctivitis, pathogens such as Pseudomonas aeruginosa, Escherichia coli, Proteus sp., Moraxella sp., and Neisseria gonorrhoeae have been isolated from conjunctival samples as etiologic agents $[8,12]$. There are also indications that these pathogens elicit dynamism in order to achieve clonal success as agents of conjunctivitis coupled with their increasing propensity to develop resistance against the commonly used antibiotics in the form of eye drops and ointment to treat conjunctivitis. Plasmids, which are extrachromosomal double-stranded DNA materials, have been found to be useful for pathogens' genetic diversity and prowess as infectious agents. Profiling pathogens for their harbored plasmids has been found to be very useful in epidemiological studies, diagnosis, and elucidation of mechanisms of drug resistance [13]. Plasmids have also been found useful in knowing whether two or more strains of a pathogen evolve from the same microorganism, thereby providing a reliable insight into the genetic relatedness of pathogens in an environment $[14,15]$.

In Nigeria, there have not been adequate data regarding etiologic agents of conjunctivitis coupled with lack of updates on trends in antibiotic resistance patterns of ocular pathogens to inform treatment guidelines in the care of eye-infected patients. This is proposed to play a role in the deteriorating eye health of patients despite the use of antibiotics.

This study was conducted to determine antibacterial susceptibility and characterize the plasmids harbored by bacteriologic agents of conjunctivitis in Lagos, Nigeria.

\section{Materials and methods}

Specimen and bacteria identification

A total of 83 consecutive and non-duplicate conjunctival specimens were collected from patients attending eye 
clinics at Lagos State University Teaching Hospital and two district hospitals in Lagos, Nigeria, between February and September 2010. The patients were clinically diagnosed to have conjunctivitis through history taking and clinical examination of the eye and were enrolled into the study after obtaining an informed consent.

Specimens were collected by swiping a broth-moistened swab across the conjunctiva of the affected eye(s) per patient. Specimens were transported in cold boxes within $4 \mathrm{~h}$ of collection. To grow bacteria, specimens were inoculated directly onto sheep blood agar, chocolate agar, MacConkey agar, and brain heart infusion broth (BHI). Colonies obtained in the primary plates and BHI cultures were further subcultured in the various solid growth media including mannitol salt agar. Direct microscopic examinations such as $10 \% \mathrm{KOH}$ wet mounting and gram staining were carried out, and each bacterial isolate was speciated via standard biochemical tests [16].

\section{Antibiotic susceptibility testing}

In vitro susceptibility to antibiotics of the bacterial isolates and transconjugants was done by the Kirby-Bauer disk diffusion method [17] on Muller-Hinton (MH) agar. An inoculum of each bacterial isolate was prepared by diluting its overnight culture to 0.5 MacFarland standard $(1.5 \times$ $10^{8} \mathrm{cfu} / \mathrm{mL}$ ) using sterile MH broth. The standard antibiotic disks used from Oxoid (UK) were chloramphenicol $30 \mu \mathrm{g}$, gentamicin $30 \mu \mathrm{g}$, ampicillin $30 \mu \mathrm{g}$, ofloxacin $5 \mu \mathrm{g}$, amoxicillin $30 \mu \mathrm{g}$, nitrofurantoin $200 \mu \mathrm{g}$, amikacin $25 \mu \mathrm{g}$, and streptomycin $30 \mu \mathrm{g}$. The results obtained were interpreted as sensitive or resistant according to the National Committee on Clinical Laboratory guidelines [18]. E. coli ATCC 25922 was used as a quality control strain.

\section{Conjugation experiment and plasmid isolation}

Conjugation experiment was carried out according to Willets [19] using rifampicin-resistant E. coli $\mathrm{DH} 5 \alpha$ as the recipient cell and seven selected representatives of Gram-negative $(n=5)$ and Gram-positive bacterial cells $(n=$ 2) as donor strains. The initial donor-to-recipient ratio of 1:20 was used for mating. Transconjugants were selected on $\mathrm{MH}$ agar plate containing $300 \mu \mathrm{g} / \mathrm{mL}$ of rifampicin and $50 \mu \mathrm{g} / \mathrm{mL}$ of ampicillin or chloramphenicol. Plasmid extraction of donor strains and transconjugants was done using the alkaline lysis method of Takahashi and Nagano [20]. Plasmid DNA bands were detected by electrophoresis on $0.8 \%$ horizontal agarose gel pre-stained with ethidium bromide $(0.5 \mu \mathrm{g} / \mathrm{mL})$ and visualized under UV light. The sizes of the plasmid DNA bands were determined by extrapolation based on the mobilities of HindIII digested $\lambda$
DNA co-electrophoresed with the plasmid DNA samples [21]. Antibiotic susceptibility assay was also carried out on the transconjugants.

\section{Statistical analysis}

Data on the complexity of infections, expressed as percentage, were analyzed using the chi-square $\left(\chi^{2}\right)$ test. A value of $P<0.05$ was considered to be significant.

\section{Results}

Over a period of 3 months, 83 consecutive and nonduplicated conjunctival specimens of patients suspected to have conjunctivitis were collected at the eye clinics of Lagos General Hospital and two district hospitals in Lagos. The profiles of Gram-positive and Gram-negative bacteria recovered from processed samples of patients suspected to be having conjunctivitis are summarized in Table 1. All the specimens were culture-positive, yielding a total of 155 bacterial isolates. Gram-positive cocci comprising $S$. aureus (27.7\%) and coagulase-negative Staphylococcus sp. (22.6\%) accounted for 50.3\% (78 of 155 ) of conjunctivitis cases, followed by Gram-positive bacilli $(22.6 \%)$, Gramnegative bacilli (21.3\%), and Gram-negative cocci (4.5\%). Corynebacterium spp. were the most commonly isolated Gram-positive bacilli, accounting for $16.1 \%$ of conjunctivitis cases. P. aeruginosa topped with $9.7 \%$ as the most common Gram-negative bacillus. Other Gram-negative bacilli in order of their isolation rates were E. coli $(6.5 \%)$, Proteus sp., (3.2\%), Klebsiella sp. (1.9\%), and Enterobacter aerogenes $(1.9 \%)$. Moraxella spp. were the only Gram-negative cocci isolated, and they accounted for $4.5 \%$ of the total conjunctival infections. Further analysis of complexity of infections showed that 25 specimens elicited mono-infections (Fig. 1), while cases of polymicrobial infections caused by two pathogens and three or more pathogens constituted $51.8 \%$ and $18.1 \%$ of conjunctivitis specimens screened, respectively (Fig. 2). The disparity in the percentage contribution of three infection patterns was significant $\left(\chi^{2}=21.8, P=1.8 \times 10^{-5}\right.$; Table 1$)$.

In vitro susceptibilities of the recovered Gram-positive and Gram-negative bacterial isolates to nine antibiotics are shown in Table 2. Chloramphenicol and ofloxacin were found to be the least and most active antibiotics tested as 99 $(63.9 \%)$ and $149(96.1 \%)$ of the 155 recovered isolates were sensitive to them. On the whole, the least susceptible pathogen was $P$. aeruginosa with sensitivities ranging from $20 \%$ to $80 \%$, while Moraxella sp. represented the most sensitive pathogen with sensitivities ranging from $71.4 \%$ to $100 \%$. Other bacterial isolates also elicited antibiotic sensitivities in the range of $33.3-100 \%$. 
Table 1 Gram-positive and Gram-negative bacteria recovered from the eyes of patients with conjunctivitis

\begin{tabular}{|c|c|c|c|c|c|c|}
\hline \multirow[t]{3}{*}{ Organism } & \multirow[t]{3}{*}{ No. $(\%)$ recovered } & \multicolumn{3}{|c|}{ Complexity of infections } & \multirow[t]{3}{*}{$\chi^{2}$} & \multirow[t]{3}{*}{$P$ value } \\
\hline & & \multirow{2}{*}{$\begin{array}{l}\text { Mono-infection } \\
\text { No. }(\%)\end{array}$} & \multicolumn{2}{|c|}{ Polymicrobial infection no. (\%) } & & \\
\hline & & & Two organisms & More than two organisms & & \\
\hline Total Gram-positive cocci & $78(50.3)$ & $25(30.1)$ & $43(51.8)$ & $15(18.1)$ & 21.8 & $1.8 \mathrm{E}-5$ \\
\hline S. aureus & $43(27.7)$ & & & & & \\
\hline Coagulase-negative Staph & $35(22.6)$ & & & & & \\
\hline Total Gram-positive bacilli & $35(22.6)$ & & & & & \\
\hline Bacillus sp. & $10(6.5)$ & & & & & \\
\hline Corynebacterium sp. & $25(16.1)$ & & & & & \\
\hline Total Gram-negative bacilli & $33(21.3)$ & & & & & \\
\hline P. aeruginosa & $15(9.7)$ & & & & & \\
\hline E. coli & $10(6.5)$ & & & & & \\
\hline Proteus sp. & $5(3.2)$ & & & & & \\
\hline Enterobacter aerogenes & $3(1.9)$ & & & & & \\
\hline Klebsiella sp. & $3(1.9)$ & & & & & \\
\hline Gram-negative cocci & $7(4.5)$ & & & & & \\
\hline Moraxella sp. & $7(4.5)$ & & & & & \\
\hline Total & $155(100)$ & & & & & \\
\hline
\end{tabular}

A total of 101 isolates were screened for plasmids, of which 45 harbored plasmids, yielding a plasmid frequency of $44.6 \%$.

Tables 3 and 4 depict outcomes of the conjugation experiment. Conjugal transfer of resistance to chloramphenicol, ampicillin, and streptomycin was detected in the transconjugants after the mating experiment. The antibiotic resistances were transferred either singly or in combination from six of the seven selected donor strains. The antibiotic resistance pattern transferred by these donor strains was partial and was associated with the transfer of $\mathrm{R}$ plasmids of sizes $21.3,15.2$, and $5.0 \mathrm{~kb}$ from three of the six transferable strains (Tables 3 and 4). The frequencies of transfer of antibiotype or $\mathrm{R}$ plasmids to the transconjugants ranged from $1.8 \times 10^{-7}$ to $1.4 \times 10^{-5}$ transconjugants per donor strain.

\section{Discussion}

The infections of the eye including conjunctivitis are a major cause of hospital consultation in Nigeria and are associated with hospitalization and mortality rates of $0.3-$ $3 \%$ [22-24]. The present study shows that conjunctivitis in Lagos is caused by multiple bacterial aetiologies involving both Gram-positive and Gram-negative pathogens with varying antibiotic susceptibility patterns and plasmid carriage ability. The transfer of antibiotic resistance and $\mathrm{R}$ plasmids by some of the recovered strains to $E$. coli was also revealed. The observed etiologic pattern of Grampositive pathogens predominated by $S$. aureus $(27.7 \%)$ and non-coagulase Staphylococci $(22.6 \%)$ as causative agents of conjunctivitis in this study is similar to previous reports by Iroha et al. [6] who reported $37.4 \%$ and $12.3 \%$ as the isolation rates for $S$. aureus and coagulase-negative Staphylococci in the same environment. In southeast Nigeria, Ubani [25] also recovered S. aureus (23.7\%) and Staphylococcus albus (19.3\%) as the predominant Gram-positive pathogens of ocular infections in patients. In other countries of the world such as India, isolation rates of $25 \%$ and $18.3 \%$ have been reported in $S$. aureus and non-coagulase Staphylococci as ocular pathogens, respectively [8]. Gen-
Fig. 1 Agarose gel electrophoresis of ocular pathogens recovered as mono-infections. Lane 1 HindIII $\lambda$ DNA markers; Lane 2 E. coli; Lanes 3-5 P. aeruginosa; Lane 6 E. aerogenes; Lane 7 K. pneumoniae; Lane 8 Moraxella sp.

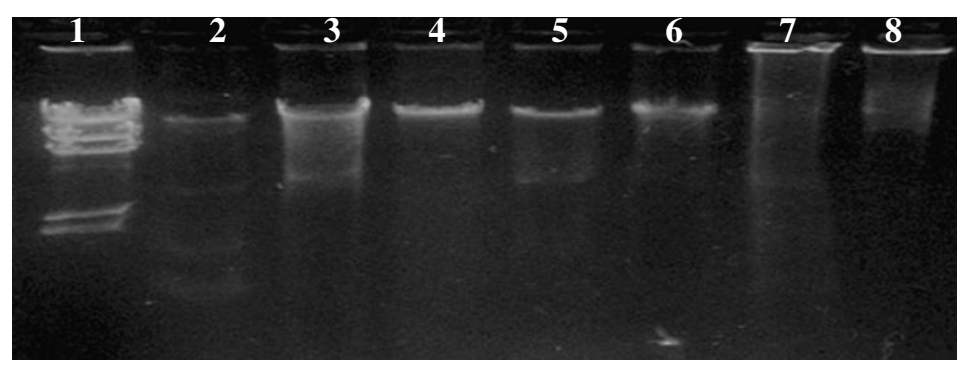




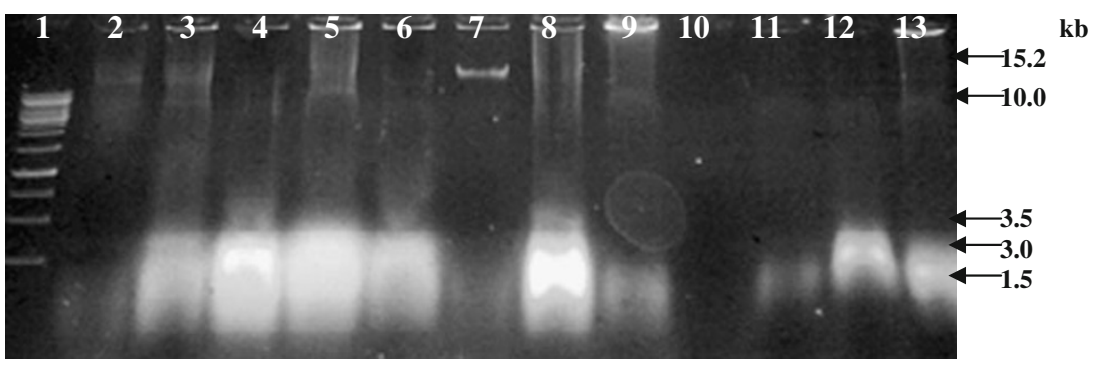

Fig. 2 Agarose gel electrophoresis of ocular pathogens recovered as polymicrobial infections. Lane 110-kb DNA marker; Lanes 2 and $3 \mathrm{~S}$. aureus; Lane 4 Bacillus sp.; Lane 5 Corynebacterium sp.; Lane 6
Bacillus sp.; Lane 7 Moraxella sp.; Lane 8 P. aeruginosa; Lane 9 Klebsiella sp.; Lane 10 negative control (sterile water); Lanes 11-13 Coagulase-negative Staphylococcus sp. erally, the predominance of Staphylococci, Bacillus sp., and Corynebacterium sp. as major ocular pathogens might be due to the fact that these organisms represent the major flora of the eye lid and the conjunctiva and under normal conditions, their clinical manifestations are averted by eye innate immune defense system constituted by tear flow, secretory immunoglobulin, and the presence of cidal agents such as lysozyme and lactoferrin [9, 26]. Other Grampositive pathogens such as $S$. pneumoniae, $S$. pyogenes, $S$. viridans, and Haemophilus influenzae were not found in this study and were not reported by Iroha et al. [6]. This suggests consistency in the Gram-positive etiology of conjunctivitis in Lagos, even though non-coagulase Staphylococci are now trending toward equality with $S$. aureus in causing conjunctivitis in the study area. Contrastingly, these pathogens were implicated as ocular pathogens in southeast Nigeria [25], India [8], Hong Kong [27], USA [12], Singapore [9], and Ghana [10], reconfirming previous reports that ocular pathogens vary in etiology in different countries and different locations within a country $[8,25$, 28]. Our non-recovery of other Gram-positive ocular pathogens may also be due to the focus of this study, which centered on conjunctivitis compared with other ocular infections included in the Indian and southeastern Nigerian studies $[8,25]$. With regards to Gram-negative pathogens in ocular infections in Lagos, we found $P$. aeruginosa as the predominating strain with an isolation rate of $9.7 \%$, whereas in a previous study in the same environment, Klebsiella pneumoniae was the most commonly isolated pathogen (12.9\%) followed by P. aeruginosa $(8.2 \%)$. Therefore, our finding indicates a changing trend in the Gram-negative etiology of conjunctivitis in Lagos. In other parts of the country, K. pneumoniae was also most commonly isolated, followed by $E$. coli coupled with the involvement of other Gram-negative pathogens such as $N$. gonorrhoeae and Neisseria meningitides. This again corroborates the influence of locations on the etiology of ocular infections. Unlike the present study, which is similar in context to the study in southeast Nigeria, the previous Lagos study focused on neonates who have predilections to infections due to E. coli and Klebsiella sp. in that age group. In the present study, the 83 conjunctival samples tested were obtained from patients of all age groups, with $10.8 \%$ being children aged $2-5$ years, $27.7 \%$ were aged $6-13$ years representing older children, $21.7 \%$ were adolescents aged $14-19$ years, and $39.8 \%$ were adults.

Our results of pathogens' antibiotic susceptibilities suggest that in vitro, chloramphenicol has deteriorated as an anti-conjunctival agent with an overall efficacy of $63.9 \%$ and being $55.8-90 \%$ and $20-71.4 \%$ effective against Grampositive and Gram-negative bacteria isolated, respectively. In an increasing order anti-conjunctival activity, other tested antibiotics' activities are streptomycin $<$ ampicillin $<$ gentamicin $<$ amoxicillin $<$ cefotaxime $<$ amikacin $<$ ceftazidime $<$ ofloxacin, with efficacy ranging from $77.4 \%$ to $96.1 \%$. In clinical context, our findings connote a possible reduction in the therapeutic relevance of chloramphenicol and gentamicin in the treatment of conjunctivitis in Lagos as these antibiotics in the form of eye drops are most commonly available and used in the study area. Given the higher anti-conjunctival efficacies of amikacin, cefotaxime, and ofloxacin, the availability as eye preparations and the empirical use of these antibiotics are strongly recommended in the management of conjunctivitis in Lagos. Elsewhere, fluoroquinolones such as ofloxacin and gatifloxacin are also the current recommended drugs of choice in the treatment of ocular infections [8-10, 29, 30]. However, to prevent and control the development of antibiotic resistance by ocular pathogens to these antibiotics and even optimize the therapeutic applications of chloramphenicol and gentamicin, institution of therapy based on the antibiogram profile of pathogens is highly essential. Furthermore, our observation that $69.9 \%$ of conjunctivitis cases screened are polymicrobial in etiology provides an indication for a complex epidemiological situation of conjunctivitis in this environment. Therefore, institution of appropriate anticonjunctival therapy in afflicted patients is very important as this would avert further complications and improve the prognosis of infection. Based on our findings, such 


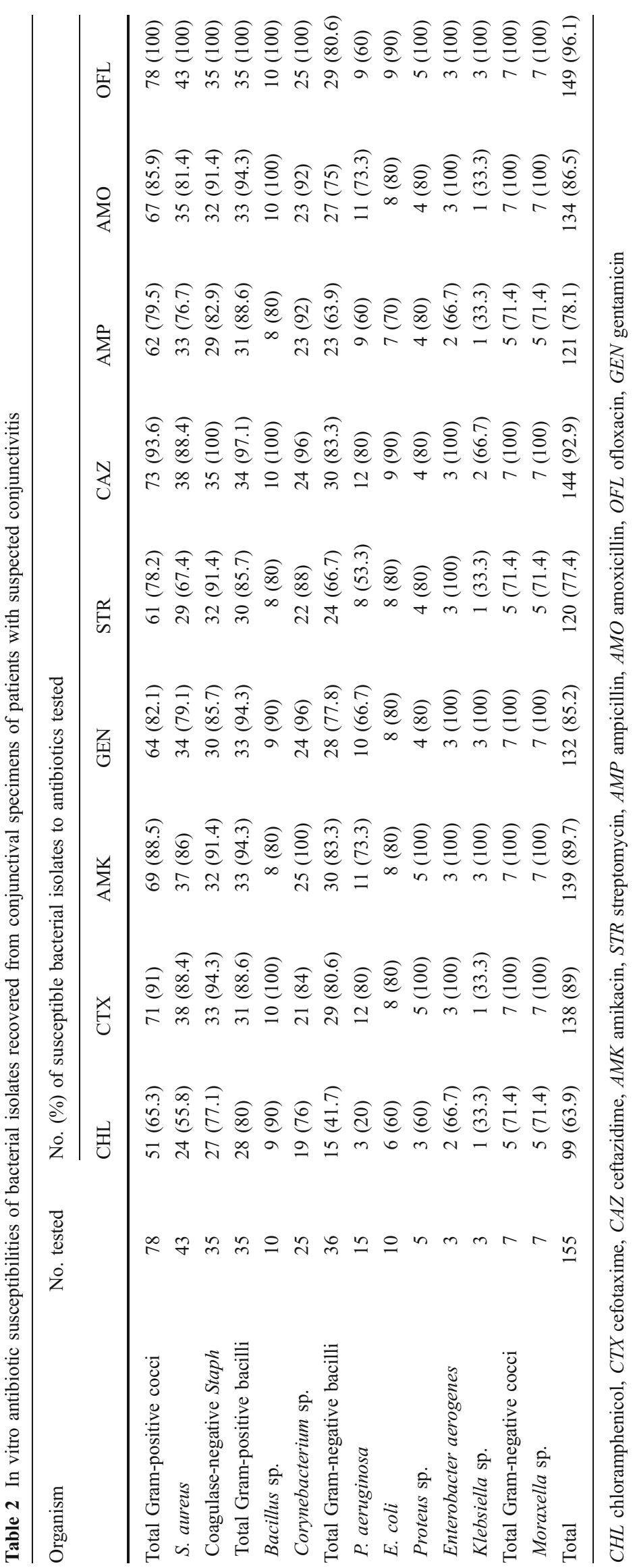


Table 3 Percentage of bacterial isolates harboring plasmids from the conjunctival specimens

\begin{tabular}{|c|c|c|c|}
\hline \multirow[t]{2}{*}{ Organism } & \multirow[t]{2}{*}{ No. tested } & \multicolumn{2}{|c|}{ No. (\%) of bacterial isolates } \\
\hline & & Plasmid-positive & Plasmid-negative \\
\hline Total Gram-positive cocci & 50 & $19(38)$ & $31(72)$ \\
\hline S. aureus & 25 & $11(44)$ & $14(56)$ \\
\hline Coagulase-negative Staph & 25 & $8(32)$ & $17(68)$ \\
\hline Total Gram-positive bacilli & 18 & $7(38.9)$ & $11(61.1)$ \\
\hline Bacillus sp. & 8 & $4(50)$ & $4(50)$ \\
\hline Corynebacterium sp. & 10 & $3(30)$ & $7(70)$ \\
\hline Total Gram-negative bacilli & 26 & $18(69.2)$ & $8(30.9)$ \\
\hline P. aeruginosa & 10 & $5(50)$ & $5(50)$ \\
\hline E. coli & 7 & $6(85.7)$ & $1(14.3)$ \\
\hline Proteus sp. & 3 & $2(66.7)$ & $1(33.3)$ \\
\hline Enterobacter aerogenes & 3 & $2(66.7)$ & $1(33.3)$ \\
\hline Klebsiella sp. & 3 & $3(100)$ & $0(0)$ \\
\hline Total Gram-negative cocci & 7 & $1(14.3)$ & $6(85.7)$ \\
\hline Moraxella sp. & 7 & $1(14.3)$ & $6(85.7)$ \\
\hline Total & 101 & $45(44.6)$ & $56(55.4)$ \\
\hline
\end{tabular}

appropriateness in medication may warrant the use of two or more antibiotics especially for cases in which both Gram-positive and Gram-negative pathogens are involved.

The present study has also documented the involvement of plasmids as factors responsible for antibiotic resistance in some of the recovered pathogens since these resistances were partly transferred to E. coli $\mathrm{DH} 5 \alpha$ by conjugation. Therefore, our findings suggest the emergence and active transfer of antibiotic resistance and $\mathrm{R}$ plasmids among the circulating strains causing conjunctivitis in Lagos. In this study, antibiotics such as chloramphenicol, streptomycin, and ampicillin were easily transferred from a multidrugresistant ocular pathogen to $E$. coli. The co-transfer of plasmids of sizes $21.5,15.2$, and $5.0 \mathrm{~kb}$ suggests that these extrachromosomal DNAs are R plasmids, even though curing experiment was not done. The minimum size of a plasmid with an efficient conjugation system has been reported to be $>15 \mathrm{~kb}$ [14]. Therefore, the presence of the $5.0-\mathrm{kb}$ plasmids in the transconjugants implies that the larger molecular size plasmids (i.e., 21.3 and $15.2 \mathrm{~kb}$ ) might serve as vehicles for the transfer of lower molecular weight plasmids such as $5.0 \mathrm{~kb}$ to $E$. coli $\mathrm{DH} 5 \alpha$. This also implies that the mechanism of plasmid mobilization among the ocular pathogens may entail the use of larger sized plasmids as vehicles in addition to the classical transfer systems such as conjugation that require considerable genetic information, as previously reported by Smith and Linggood [31], Achmith and Helmuth [32], Christiansen et al. [33], and Jamieson and Bremner [14]. The result from the conjugation experiment also revealed that the varied

Table 4 Conjugal transfer of antibiotic resistance and plasmids to E. coli DH5 $\alpha$ by some of the selected bacterial isolates recovered from patients with conjunctivitis

\begin{tabular}{|c|c|c|c|c|c|}
\hline Donor strain & Antibiotype & Plasmid profile & $\begin{array}{l}\text { Antibiotype } \\
\text { transferred to E. coli } \mathrm{DH} 5 \alpha\end{array}$ & $\begin{array}{l}\text { R plasmid transferred } \\
\text { to } E \text {. coli } \mathrm{DH} 5 \alpha\end{array}$ & $\begin{array}{l}\text { Conjugation } \\
\text { frequency }^{\mathrm{a}}\end{array}$ \\
\hline P. aeruginosa $\mathrm{NG}-02$ & Chl Str Amp Gen & $21.3,5.0,1.2,1.0$ & Chl Str Amp & $21.3,5.0$ & $1.8 \times 10^{-7}$ \\
\hline P. aeruginosa $\mathrm{NG-07}$ & Amo Amp Ctx Ofl & 21.3 & Amp & - & $1.4 \times 10^{-5}$ \\
\hline E. coli $\mathrm{NG}-05$ & Chl Amp Str Amk & $21.3,5.0$ & Amp Str & 21.3 & $1.9 \times 10^{-7}$ \\
\hline E. coli $\mathrm{NG}-01$ & Chl Amp Gen Amo & $15.2,10.0,4.1$ & Chl Amp & 15.2 & $1.8 \times 10^{-6}$ \\
\hline Klebsiella oxytoca $\mathrm{NG}-03$ & Chl Str & $4.1,2.7$ & $\mathrm{Chl}$ & - & $2.1 \times 10^{-7}$ \\
\hline S. aureus NG-18 & Amp Str Amo & $15.2,9.0,5.0,2.0$ & Str & - & $1.9 \times 10^{-5}$ \\
\hline S. epidermidis NG-22 & Chl Amp Str & $15.2,2.0$ & - & - & ND \\
\hline
\end{tabular}

ND not determined, Chl chloramphenicol, Amp ampicillin, Str streptomycin, Amo amoxicillin, Gen gentamicin, Amk amikacin, Ofl ofloxacin, Ctx cefotaxime

${ }^{\text {a }}$ Conjugation frequency is defined as the number of transconjugants as a proportion of total bacterial count in the nonselective medium 
drug-resistant exconjugants arose at a frequency range of $10^{-5}-10^{-7}$ per donor cell. These evolution rates are similar to those of previously reported epidemiological and clinically important pathogens in Nigeria, and some of these pathogens were also recovered in this study. They include P. aeruginosa [34], E. coli [35], and Staphylococci [36]. Of further clinical importance is the fact that the organisms recovered here have also been implicated in the pathogenesis of other non-ocular infections such as diarrhea illnesses, urinary tract infections, sepsis, bacteremia, pneumonia, and meningitis [37-39]. In these infections, resistance rates higher than what we found for the least and most active anti-conjunctival antibiotics in this study were reported [38, 39]. Therefore, our antibiogram results indicate that the conjunctivitis cases studied bacteriologically are probably exogenous in origin. This possibility is further supported by the fact that all the patients studied are outpatients ruling out nosocomial ocular infections. The prevalence rate of plasmids of $44.6 \%$ can be said to be high, and this is synonymous with pathogens that elicit resistance to two or more antibiotics. Lower plasmid prevalence rates have been reported for pathogens such as $P$. aeruginosa [40], while higher rates have been reported for multidrug-resistant strains of E. coli and K. pneumoniae in epidemiological studies [41]. In this study, plasmids having a size range of 5.0-12.5 $\mathrm{kb}$ were common among the Gram-negative pathogens and those of $2.7-4.1 \mathrm{~kb}$ were common among the Gram-positive pathogens irrespective of the species affiliations, suggesting genetic diversity disparity but yet active transfer of plasmids and associated antibiotic resistances among the ocular pathogens in causing polymicrobial infections in patients with conjunctivitis in Lagos.

The implications of the results obtained from this study are twofold. First, the epidemiological situation of conjunctivitis is more complex than previously thought in this environment. Secondly, the etiologic agents harboring plasmids have the potentials of disseminating antibiotic resistance and their associated plasmids to other causative agents without plasmids that were previously sensitive to the commonly used anti-conjunctival agents in Lagos. To avert these implications, there is a need to carry out regular surveillance of agents of conjunctivitis in Lagos for antibiotic susceptibility and plasmid carriage in order to develop an appropriate strategy to prevent the spread of antibiotic resistance among pathogens and control conjunctivitis. Further studies are required using, apart from plasmid curing, techniques such as polymerase chain reaction and drug resistance phenotyping methods for better understanding of mechanisms to antibiotic resistance by Gram-positive and Gram-negative pathogens responsible for conjunctivitis and other ocular infections in Nigeria. Studies are also needed to understand the pathogenic disposition of some of these isolates, vis-a-vis the virulent factors they express using both in vitro and in vivo model systems. This is because the conjunctiva and cornea sac for instance naturally accommodate avirulent microbes as flora, and these organisms can be co-recovered from clinical eye specimens in patients with eye problems $[9,26]$.

Nevertheless, based on the findings of this study, it can be concluded that conjunctivitis as an eye problem in Lagos is polymicrobial with infections eliciting low and high sensitivity to chloramphenicol and ofloxacin, respectively. Infections are also associated with transferable $\mathrm{R}$ plasmids for chloramphenicol, ampicillin, and streptomycin. Continuous surveillance of conjunctivitis in relation to etiology, drug susceptibility, plasmid transferability, and mechanisms of resistance for epidemiological control in the study area is therefore recommended.

Open Access This article is distributed under the terms of the Creative Commons Attribution License which permits any use, distribution and reproduction in any medium, provided the original author(s) and source are credited.

\section{References}

1. Carmichael TR, Wolpert M, Koornhof HJ (1985) Corneal ulceration at an urban African hospital. Br J Ophthalmol 69:920-926

2. Sharma S (1988) Ocular microbiology, 1st edn. Aravind Eye Hospital Publication, Madurai

3. Uy HS, Tuano PM (2007) Preseptal and orbital cellulitis in a developing country. Orbit 261:33-37

4. Rahman I, Mano A, Cook AE, Leatherbarrow AE (2003) Mortality following exenteration for malignant tumours of the orbit. Br J Ophthalmol 89:1445-1448

5. Parrott WF (1971) An epidemic called Apollo. An outbreak of conjunctivitis in Nigeria. Practitioner 206:253-255

6. Iroha EO, Kesah CN, Egri-Okwaji MT, Odugbemi TO (1998) Bacterial eye infection in neonates, a prospective study in a neonatal unit. West Afr J Med 17:168-172

7. Abiose A, Bhar IS, Allanson MA (1980) The ocular health status of postprimary school children in Kaduna, Nigeria: report of a survey. J Pediatr Ophthalmol Strabismus 17:337-340

8. Ramesh S, Ramakrishnan R, Bharathi MJ, Amuthan M, Viswanathan S (2010) Prevalence of bacterial pathogens causing ocular infections in South India. Indian J Pathol Microbiol 53:281-286

9. Khosravi AD, Mehdinejad M, Heidari M (2007) Bacteriological findings in patients with ocular infection and antibiotic susceptibility pattern of isolated pathogens. Singapore Med J 48:741-743

10. Hagan M, Wright E, Newman M, Dolin P, Johnson G (1995) Causes of suppurative keratitis in Ghana. Br J Ophthalmol 79:1024-1028

11. Boralkar AN, Dindore PR, Fule RP, Bangde BN, Albel MV, Saoji AM (1989) Microbiological studies in conjunctivitis. Indian J Ophthalmol 37:94-95

12. Liesegang TJ, Forster RK (1980) Spectrum of microbial keratitis in South Florida. Am J Ophthalmol 90:38-47

13. Falkow S (1975) Infectious multiple drug resistance. Pion, London, pp 253-271

14. Jamieson AF, Bremner DF (1979) Characterization of plasmids from antibiotic-resistant Shigella isolates by agarose gel electrophoresis. J Gen Microbiol 113:73-81 
15. Litwin CM, Storm AL, Chipowsky S, Ryan KJ (1991) Molecular epidemiology of Shigella infections: plasmid profiles, serotype correlation, and restriction endonuclease analysis. J Clin Microbiol 29:104-108

16. Barrow GI, Feltham RK (1993) Cowan and Steel's manual for the identification of medical bacteria, 3rd edn. Cambridge University Press, Cambridge

17. Bauer AW, Kirby WMM, Sherrls JC, Turck M (1966) Antibiotic susceptibility testing by a standardized single disk method. Am J Pathol 45:493-496

18. National Committee for Clinical Laboratory Standards (2003) Performance standards for antimicrobial susceptibility testing13th informational supplement: approved standard M100-S13 (M2). NCCLS, Villanova

19. Willets N (1988) Conjugation. Methods Microbiol 21:49-75

20. Takahashi S, Nagano Y (1984) Rapid procedure for isolation of plasmid DNA and application to epidemiological analysis. J Clin Microbiol 20:608-613

21. Meyers JAD, Sanchez LP, Elwell P, Falkow S (1976) Simple agarose gel electrophoretic method for the identification and characterization of plasmid deoxyribonucleic acid. J Bacteriol 127:1529-1537

22. Ayanniyi AA, Mahmoud AO, Olatunj FO (2010) Causes and prevalence of ocular morbidity among primary school children in Ilorin, Nigeria. Niger J Clin Pract 13(3):248-253

23. Omoti AE, Ogbedo E (2007) Ophthalmic mortality in a tertiary centre in Nigeria. Niger Postgrad Med J 14:54-56

24. Fafowora OF, Ubah JN (1999) Mortality on an ophthalmic ward. West Afr J Med 18:211-213

25. Ubani UA (2009) Bacteriology of external ocular infections in Aba, South Eastern Nigeria. Clin Exp Optom 92:482-489

26. McClellan KA (1997) Mucosal defense of the outer eye. Surv Ophthalmol 42:233-246

27. Houang E, Larn D, Fan D, Seal D (2001) Microbial keratitis in Hong Kong: relationship to climate, environment and contact lens disinfection. Trans R Soc Trop Med Hyg 95:361-367

28. Alvarez H, Tabbara KF (1996) Infections of the eyelid. In: Tabbara KF, Hyndiuk RA (eds) Infections of the eye, 2nd edn. Little Brown and Company, Boston, pp 559-570

29. Gaynor BD, Chidambaram JD, Cevallos V, Miao Y, Miller K, Jha $\mathrm{HC}$ et al (2005) Topical ocular antibiotics induce bacterial resistance at extra-ocular sites. Br J Ophthalmol 89:1097-1099
30. Ooishi M, Miyao M (1997) Antibiotic sensitivity of recent clinical isolates from patients with ocular infections. Ophthalmologica 211:15-24

31. Smith HR, Linggood MA (1970) Transfer factors in Escherichia coli with particular regard to their incidence in enteropathogenic strains. J Gen Microbiol 62:287-299

32. Achtman N, Helmuth R (1974) The F factor carries an operon of more than $15 \times 10^{6}$ daltons coding for deoxyribonucleic acid transfer and surface exclusion. In: Schlessinger D (ed) Microbiology. American Society for Microbiology, Washington, pp 95-103

33. Christiansen C, Christiansen G, Bak AL, Stenderup A (1973) Extra-chromosomal deoxyribonucleic acid in different enterobacteria. J Bacteriol 114:367-377

34. Adetosoye AI (1980) Transmissible drug resistance in human and animal trains of Enterobacteriaceae and Pseudomonas aeruginosa. Res Vet Sci 29:342-345

35. Niemogha MT, Adewole TA, Ikea JA, Olukoya DK, Atoyebi AO, Iwalokun BA, Egbuna KN, Olukosi YA (2010) Trends in cotrimoxazole resistance among clinical isolates of Escherichia coli from Nigeria 1989-2009. International J Malaria and Trop Dis 6:181-188

36. Obi CL, Iyiegbuniwe AE, Olukoya DK, Babalola C, Igumbor EO, Okonta AA (1996) Antibiograms and plasmids of Staphylococcus aureus and coagulase negative staphylococci isolated from different clinical sources. Cent Afr J Med 42:258-261

37. Ako-Nai AK, Ogunniyi AD, Lamikanra A, Torimiro SE (1991) The characterisation of clinical isolates of Staphylococcus aureus in Ile-Ife, Nigeria. J Med Microbiol 34:109-112

38. Falade AG, Lagunju IA, Bakare RA, Odekanmi AA, Adegbola RA (2009) Invasive pneumococcal disease in children aged $<5$ years admitted to 3 urban hospitals in Ibadan, Nigeria. Clin Infect Dis 48: S190-S196

39. Adeyemi AI, Sulaiman AA, Solomon BB, Chinedu OA, Victor IA (2010) Bacterial bloodstream infections in HIV-infected adults attending a Lagos teaching hospital. J Health Popul Nutr 28:318-326

40. Plesiat P, Alkhalaf B, Michel-Briand Y (1988) Prevalence and profiles of plasmids in Pseudomonas aeruginosa. Eur $\mathrm{J}$ Clin Microbiol 7:261-264

41. Laufs R, Kleimann F (1978) Antibiotic resistance factors and other plasmids in bacterial isolates from hospitalized patients. Zentralbl Bakteriol Orig A 240:503-516 